\title{
Recycling of a perfluoroalkylated BINOL ligand using fluorous solid-phase extraction $\uparrow$
}

\author{
John Fawcett, Eric. G. Hope, Alison M. Stuart* and Andrew J. West \\ Received 2nd December 2004, Accepted 3rd February 2005 \\ First published as an Advance Article on the web 25th March 2005 \\ DOI: $10.1039 / b 418039 a$
}

After the asymmetric addition of allyltri- $n$-butyltin to benzaldehyde, a perfluoroalkylated BINOL-Sn complex was separated from the organic product using fluorous reverse phase silica gel. The lightly fluorinated ligand was then recovered by hydrolysis of the $\mathrm{R}_{\mathrm{f} 6}-\mathrm{BINOL}-\mathrm{Sn}$ complex with dilute hydrochloric acid and was reused three times without loss of activity or enantioselectivity.

\section{Introduction}

The fluorous biphase system has been applied successfully to a wide range of homogeneous catalyses with excellent catalyst recovery and reuse being reported. ${ }^{1}$ However, it is unlikely to be exploited commercially because of intersolvent leaching problems, the prohibitive expense of the perfluorocarbon solvents and concerns about their environmental persistence. An alternative approach, designed by Curran for high throughput organic synthesis, uses fluorous reverse phase (FRP) silica gel as a solid support for the separation of fluorous-tagged products from non-fluorinated reagents, as well as the removal of perfluoroalkylated reagents from organic products. ${ }^{1-3}$ The major advantages of fluorous solidphase extraction are that fewer and shorter fluorous ponytails are required $(<40 \%$ fluorine content by molecular weight) compared to liquid-liquid extraction using the FBS $(>60 \%$ fluorine content by molecular weight) and perfluorocarbon solvents are no longer required for either the reaction or separation step. Recently, we reported the first example of

$\uparrow$ This work was presented at the Green Solvents for Synthesis Meeting, held in Bruchsal, Germany, 3-6 October 2004.

*amc17@le.ac.uk

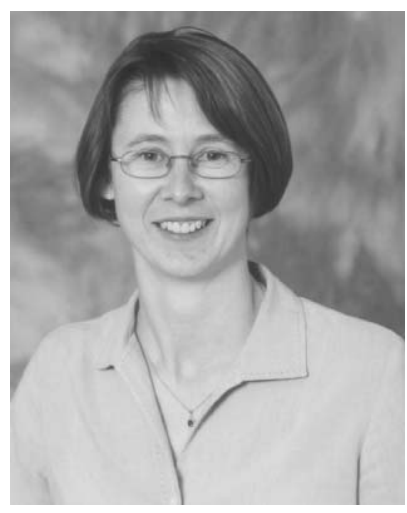

Alison Stuart studied chemistry at the University of St Andrews and obtained her PhD in organofluorine chemistry with Paul Coe at the University of Birmingham in 1996. After a postdoctoral appointment with Eric Hope at the University of Leicester in fluorous biphase catalysis, she was awarded a two year fellowship with Lloyd's Tercentenary Foundation in 1999 and a Royal Society University Research Fellowship in 2000. Currently, her research Alison Stuart is focussed on the applications of fluorous chemistry in organic synthesis as well as homogeneous catalysis. separation, recovery and recycle of a perfluoroalkylated Lewis acid catalyst, $\left[\mathrm{Ni}\left\{\mathrm{C}_{6} \mathrm{~F}_{13} \mathrm{C}(\mathrm{O}) \mathrm{CHC}(\mathrm{O}) \mathrm{C}_{6} \mathrm{~F}_{13}\right\}_{2}\right]$, using FRP silica gel after catalyzing the reaction between 2,4-pentanedione and ethylcyanoformate in dichloromethane. ${ }^{4}$ We have also extended the applications of this novel separation technique in order to recover and recycle lightly fluorinated BINAP ligands after the ruthenium-catalysed asymmetric hydrogenation of methyl acetoacetate. ${ }^{5}$ Here, we demonstrate the efficient separation and recycle of a perfluoroalkylated BINOL ligand using fluorous solid-phase extraction. ${ }^{6}$

\section{Results and discussion}

The three step synthesis of the perfluoroalkylated BINOL ligand $\left(\mathbf{1} ; \mathbf{H}_{\mathbf{2}} \mathbf{L}\right)$ is outlined in Scheme 1 and was developed originally for the preparation of fluorous-derivatised BINAP ligands. ${ }^{5,7}$ After protecting the binaphtholic groups, the perfluoroalkyl groups were attached directly to the binaphthyl backbone by a copper-mediated cross-coupling reaction using perfluorohexyl iodide. Sodium ethoxide was then used to remove the acetyl protecting groups giving the air-stable $R_{\mathrm{f}^{-}}$ BINOL ligand which partitions preferentially $(73: 27)$ into the organic phase of a toluene : perfluoro-1,3-dimethylcyclohexane biphase even though it contains 54\% fluorine content by molecular weight.

Initially, the reactivity and enantioselectivity of $(R)-\mathrm{R}_{\mathrm{f} 6^{-}}$ BINOL (1) was evaluated in the asymmetric addition of diethylzinc to benzaldehyde (Scheme 2) and compared directly with $(R)$-BINOL using the methodology developed by Chan and co-workers. ${ }^{8}$ An excess of titanium tetraisopropoxide and diethylzinc was used to ensure high conversion and enantioselectivity. Each reaction was repeated three times and the results from both systems proved to be highly reproducible. Although similar conversions were obtained in each case (Table 1), the product enantioselectivities were slightly lower when $(R)-\mathrm{R}_{\mathrm{f6}}$-BINOL was used in place of $(R)$-BINOL.

Once it had been established that the fluorinated BINOL ligand was effective in the asymmetric alkylation of benzaldehyde, the separation and recovery of the $\mathrm{R}_{\mathrm{f} 6}$-BINOL ligand was investigated. At the end of the reaction, dilute hydrochloric acid was added to quench the excess diethylzinc. The organic layer was separated, dried, concentrated in vacuo and 

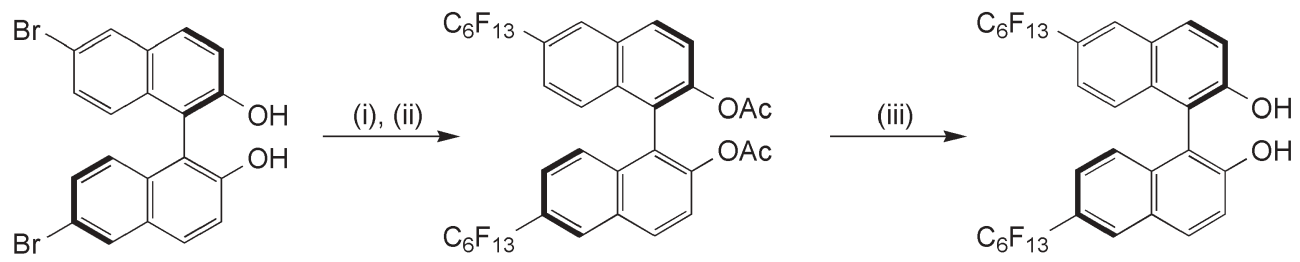

(1)

Scheme 1 (i) $\mathrm{Ac}_{2} \mathrm{O}, \mathrm{Et}_{3} \mathrm{~N}$, DMAP, DCM, reflux; (ii) $\mathrm{C}_{6} \mathrm{~F}_{13} \mathrm{I}, \mathrm{Cu}, 2,2^{\prime}$-bipy, DMSO, $\mathrm{C}_{6} \mathrm{H}_{5} \mathrm{~F}, 80{ }^{\circ} \mathrm{C}$; (iii) $\mathrm{NaOEt}$, MeOH, rt.

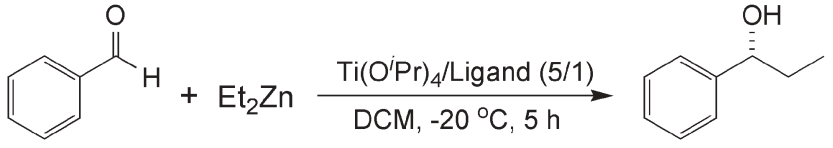

Scheme 2

Table 1 Asymmetric addition of diethylzinc to benzaldehyde ${ }^{a}$

\begin{tabular}{lll}
\hline Ligand & Conversion $(\%)^{b}$ & ee $(\%)^{c}$ \\
\hline$(R)-\mathrm{BINOL}$ & 88 & 89 \\
$(R)-\mathrm{R}_{\mathrm{f} 6}-\mathrm{BINOL}$ & 88 & 74
\end{tabular}

${ }^{a}$ Benzaldehyde $(1.20 \mathrm{mmol}), \quad \mathrm{Et}_{2} \mathrm{Zn} \quad(3.12 \mathrm{mmol}), \quad \mathrm{Ti}\left(\mathrm{O}^{i} \mathrm{Pr}\right)_{4}$ $(0.96 \mathrm{mmol})$ and ligand $(0.21 \mathrm{mmol})$ in DCM $(10 \mathrm{ml}),-20{ }^{\circ} \mathrm{C}, 5 \mathrm{~h}$.

${ }^{b}$ Percent conversion determined by ${ }^{1} \mathrm{H}$ NMR spectroscopy. ${ }^{c}$ ee determined by chiral gc.

then added to the top of a short column of FRP silica gel. Acetonitrile was used to elute the organic product, but ${ }^{1} \mathrm{H}$ and ${ }^{19}$ F NMR spectroscopy revealed that the 1-phenyl-propan-1-ol product was contaminated with $(R)-\mathrm{R}_{\mathrm{f} 6}-\mathrm{BINOL}$. Unfortunately, it was not possible to separate the alcohol product from the lightly fluorinated analogue of BINOL using fluorous solid-phase extraction because (1) is still a relatively polar compound. A highly fluorinated BINOL derivative that contains six fluorous ponytails has, however, been recycled successfully using FRP silica gel after the asymmetric addition of diethylzinc to aromatic aldehydes in high conversions and good enantioselectivities. ${ }^{9}$ Unfortunately, the disadvantage of this methodology was that the expensive fluorous solvent, perfluorohexane, was used to recover the highly fluorous BINOL ligand from the column.

We have also investigated the catalytic application of the Ti$\mathrm{R}_{\mathrm{f6}}$-BINOL system in the asymmetric allylation of benzaldehyde using allyltri- $n$-butyltin (Scheme 3 ). Zhao and co-workers ${ }^{10}$ have studied this reaction and obtained good conversions and enantioselectivities in a perfluorohexanehexane biphase, but reported significant leaching (24\%) of the lightly fluorinated BINOL ligand into the organic phase. Initially, we used the conditions developed by Zhao and coworkers with only slight modifications. Dichloromethane was used as the reaction solvent because $(R)$-BINOL is insoluble in hexane. Good conversions were obtained for both $(R)$-BINOL

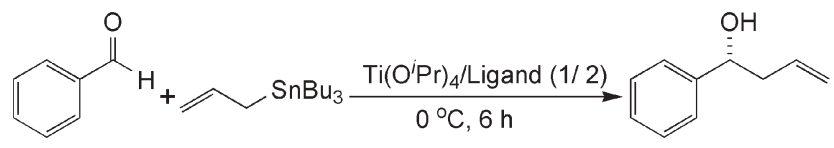

Scheme 3 and $(R)-\mathrm{R}_{\mathrm{f} 6}$-BINOL (Table 2), but once again, the enantioselectivity was slightly lower when the fluorinated BINOL ligand was used in dichloromethane. However, by changing the solvent to hexane the enantioselectivity increased to $75 \%$ ee demonstrating that the perfluoroalkyl groups do not have a detrimental effect on the abilities of the modifying ligand.

In the separation and recycling studies both the fluorous and non-fluorous catalyses were carried out in dichloromethane to enable the direct comparison between $(R)-\mathrm{R}_{\mathrm{f} 6}$-BINOL and conventional $(R)$-BINOL. The separation of $(R)$-BINOL from the organic product, 4-phenyl-1-buten-4-ol, was first investigated on conventional silica gel. Since allyltri- $n$-butyltin was added in a stoichiometric amount, it was not necessary to carry out an acid wash and so the crude reaction mixture was concentrated in vacuo before being loaded on to the top of a short column of silica gel. The 4-phenyl-1-buten-4-ol product was eluted from the column with acetonitrile and analysis by ${ }^{1} \mathrm{H}$ NMR spectroscopy showed that it was contaminated with an $(R)$-BINOL-containing species that also gave rise to butyl peaks. Tin NMR spectroscopic studies confirmed the presence of tin in this byproduct and all attempts to separate this contaminant from the desired product by solid-phase extraction were unsuccessful. In a further attempt to carry out this separation, the concentrated reaction mixture was left to stand overnight and some crystals suitable for X-ray analysis were formed in the residue. The crystal structure revealed that a monodeprotonated BINOL (HL)-tributyltin polymer was formed; selected bond length and bond angle data are given in Table 3. The structure of the monomeric repeat unit (Fig. 1) shows that tributyltin binds tightly to the deprotonated naphthoxy atom of BINOL and forms a much weaker interaction with the naphthol oxygen atom of an adjacent repeat unit to generate a polymeric chain containing alternating $\mathrm{SnBu}_{3}$ and monodeprotonated BINOL units (Fig. 2). The highly distorted trigonal bipyramidal tin environment, in which the tributyl groups are displaced towards the neutral donor group, is very similar to the coordination geometry adopted by $\left[\mathrm{SnPh}_{3}\left(\mathrm{O}^{i} \mathrm{Bu}\right)\left(\mathrm{HO}^{i} \mathrm{Bu}\right)\right],{ }^{11}$ which has analogous

Table 2 Asymmetric addition of allyltri- $n$-butyltin to benzaldehyde ${ }^{a}$

\begin{tabular}{llll}
\hline Ligand & Solvent & Conversion $(\%)^{b}$ & ee $(\%)^{c}$ \\
\hline$(R)-\mathrm{BINOL}$ & Dichloromethane & 89 & 79 \\
$(R)-\mathrm{R}_{\mathrm{f} 6}$-BINOL & Dichloromethane & 85 & 66 \\
$(R)-\mathrm{R}_{\mathrm{f} 6}$-BINOL & Hexane & 88 & 75
\end{tabular}

${ }^{a}$ Benzaldehyde $(1 \mathrm{mmol})$, allyltri- $n$-butyltin $(1.1 \mathrm{mmol}), \mathrm{Ti}\left(\mathrm{O}^{i} \mathrm{Pr}\right)_{4}$ $(0.1 \mathrm{mmol})$, ligand $(0.2 \mathrm{mmol}), 0{ }^{\circ} \mathrm{C}, 6 \mathrm{~h}$. ${ }^{b}$ Percent conversion determined by ${ }^{1} \mathrm{H}$ NMR spectroscopy. ${ }^{c}$ ee determined by conversion into the Mosher's acid ester followed by gc analysis. 
Table 3 Selected bond lengths $(\AA)$ and bond angles $\left(^{\circ}\right)$ for $\left[\mathrm{SnBu}_{3}(2-\right.$ O-2'-HO-1,1'-binaphthol) $]_{n}{ }^{a}$

\begin{tabular}{lllc}
\hline $\mathrm{Sn}(1)-\mathrm{C}(1)$ & $2.138(5)$ & $\mathrm{C}(1)-\mathrm{Sn}(1)-\mathrm{O}(2)$ & $92.45(19)$ \\
$\mathrm{Sn}(1)-\mathrm{C}(5)$ & $2.142(5)$ & $\mathrm{C}(5)-\mathrm{Sn}(1)-\mathrm{O}(2)$ & $95.24(18)$ \\
$\mathrm{Sn}(1)-\mathrm{C}(9)$ & $2.171(5)$ & $\mathrm{C}(9)-\mathrm{Sn}(1)-\mathrm{O}(2)$ & $99.4(2)$ \\
$\mathrm{Sn}(1)-\mathrm{O}(2)$ & $2.142(4)$ & $\mathrm{C}(1)-\mathrm{Sn}(1)-\mathrm{C}(5)$ & $126.2(2)$ \\
$\mathrm{Sn}(1)-\mathrm{O}(1) \# 1$ & $2.549(4)$ & $\mathrm{C}(1)-\mathrm{Sn}(1)-\mathrm{C}(9)$ & $114.3(2)$ \\
$\mathrm{O}(1)-\mathrm{Sn}(1) \# 2$ & $2.549(4)$ & $\mathrm{C}(5)-\mathrm{Sn}(1)-\mathrm{C}(9)$ & $116.7(2)$ \\
$\mathrm{O}(1)-\mathrm{C}(13)$ & $1.383(7)$ & $\mathrm{C}(5)-\mathrm{Sn}(1)-\mathrm{O}(1) \# 1$ & $80.77(17)$ \\
$\mathrm{O}(2)-\mathrm{C}(24)$ & $1.363(6)$ & $\mathrm{C}(1)-\mathrm{Sn}(1)-\mathrm{O}(1) \# 1$ & $87.55(18)$ \\
& & $\mathrm{O}(2)-\mathrm{Sn}(1)-\mathrm{O}(1) \# 1$ & $175.01(13)$
\end{tabular}

${ }^{a}$ Symmetry transformations used to generate equivalent atoms: \#1 $-x, y-1 / 2,-z+1 ; \# 2-x, y+1 / 2,-z+1$.

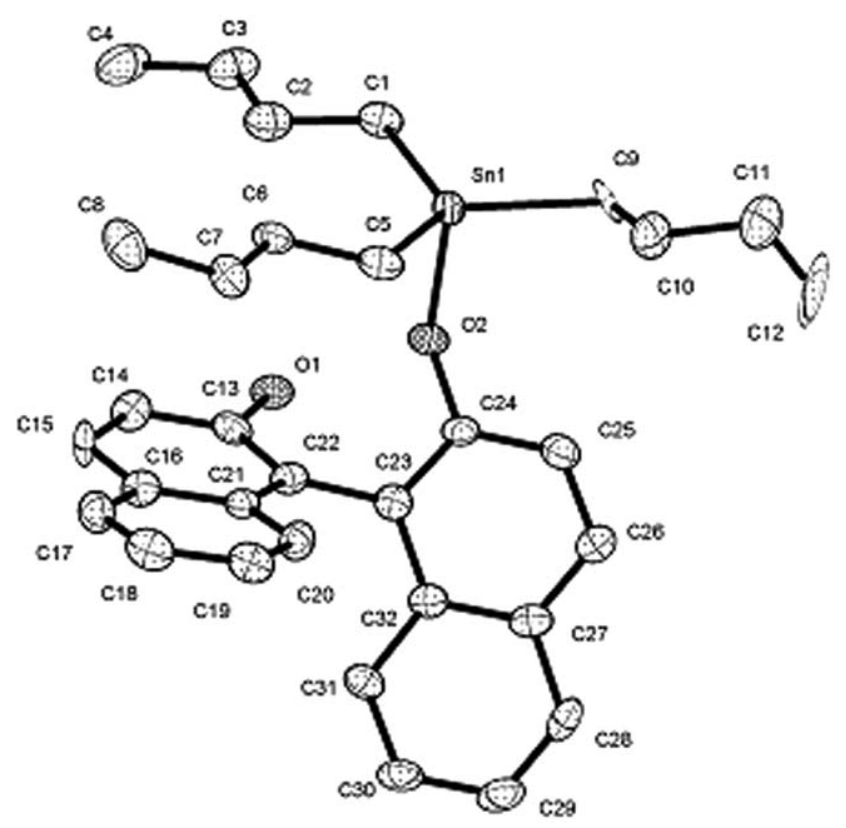

Fig. 1 Crystal structure of $\left[\mathrm{SnBu}_{3}(2-\mathrm{O}-2 \text { '-HO-1,1'-binaphthol) }]_{n}\right.$ repeat unit. Displacement ellipsoids are shown at the $50 \%$ probability level. The $\mathrm{H}$ atoms are omitted for clarity.

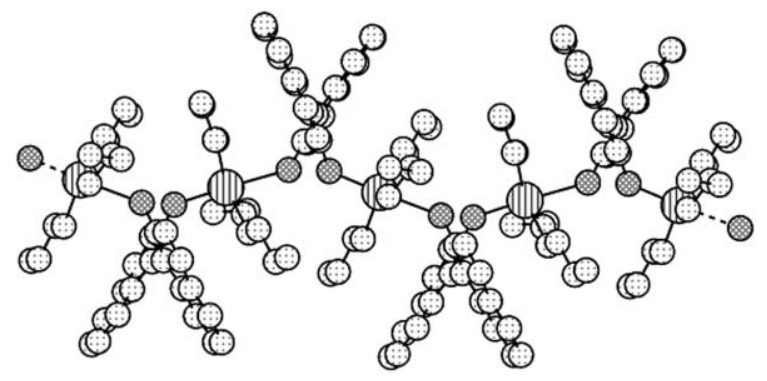

Fig. 2 Extended solid-state structure of $\left[\mathrm{SnBu}_{3}\left(2-\mathrm{O}-2^{\prime}-\mathrm{HO}-\right.\right.$ 1,1'-binaphthol) $]_{n}$. The $\mathrm{H}$ atoms are omitted for clarity.

Sn-O distances of 2.065(5) and 2.550(6) $\AA$. The number of crystallographically characterized monodeprotonated BINOL (HL) complexes is relatively small, but the polymeric structure observed here is very similar to that reported recently for $\left[\mathrm{Li}((R)-\mathrm{HBINOL})(\mathrm{THF})_{2}\right]_{n}{ }^{12}$

After carrying out the asymmetric catalysis with $(R)-\mathrm{R}_{\mathrm{f} 6^{-}}$ BINOL, the concentrated crude reaction mixture was added to the top of a short column of FRP silica gel. This time elution with acetonitrile gave clean product without any BINOL impurites. After an acid wash of the product, ICP atomic emission spectroscopy revealed that there was only a very small amount of tin $(1.24 \mathrm{ppm} \equiv 0.02 \%$ of the original amount of tin added) and titanium ( $2.21 \mathrm{ppm} \equiv 0.88 \%$ of the original amount of titanium added) leaching into the product. Once the product was removed completely from the column with acetonitrile, a solvent switch to diethyl ether was then used to recover the $\mathrm{R}_{\mathrm{f} 6}-\mathrm{BINOL}$ containing species. From ${ }^{1} \mathrm{H}$ and ${ }^{119} \mathrm{Sn}\left\{{ }^{1} \mathrm{H}\right\}$ NMR spectroscopic studies of this material, it is believed that a non-polar, $\mathrm{R}_{\mathrm{f} 6}$-BINOL-Sn polymer is also formed in this system and this accounts for the ability to isolate the organic product without $\mathrm{R}_{\mathrm{f} 6}$-BINOL contamination in contrast to our earlier work on the asymmetric alkylation of benzaldehyde with diethylzinc. When the isolated material was dried and reused in a second catalytic run with fresh aliquots of $\operatorname{Ti}\left(\mathrm{O}^{i} \mathrm{Pr}\right)_{4}$, benzaldehyde and allyltri- $n$-butyltin, only unreacted starting materials were recovered. However, it is possible to recover $(R)-\mathrm{R}_{\mathrm{f} 6}-\mathrm{BINOL}$ from the $\mathrm{R}_{\mathrm{f} 6}-\mathrm{BINOL}-\mathrm{Sn}$ polymer by hydrolysis with $4 \mathrm{M}$ hydrochloric acid and this recovered $(R)-\mathrm{R}_{\mathrm{f} 6}-\mathrm{BINOL}$ ligand was then reused in three further catalytic runs (Table 4).

The data show that similar product conversions are achieved after each run, with a slight fall after the third ligand reuse that is most likely to be caused by mechanical losses of the ligand after each recycle. There is also a small decrease in the product enantioselectivity probably due to a small amount of ligand racemisation. Only very low levels of tin and titanium leaching into the organic product were obtained and the amount of tin and titanium in the product could be removed to below detectable levels by simply passing the product, after separation on the FRP column, through a second short column of silica gel using acetonitrile as the eluant.

A subsequent investigation of alternative solid supports (powdered PTFE, $\mathrm{C}_{8}$ reverse phase silica gel and conventional silica gel) demonstrated that FRP silica gel is essential for the efficient separation of the $(R)-\mathrm{R}_{\mathrm{f} 6}$-BINOL-Sn complex from the organic product, since leaching of the $\mathrm{R}_{\mathrm{f} 6}$-BINOL complex into the product was obtained with all of these alternative solid supports. Although the separation procedure was established originally after asymmetric allylation in dichloromethane, exactly the same recycling protocol can be used after catalysis in hexane when the product was obtained in higher enantioselectivity $\left(78 \%\right.$ ee). Analysis of the product by ${ }^{1} \mathrm{H}$ NMR spectroscopy and ICP atomic emission spectroscopy showed that it was isolated without any ligand contamination and only low levels of tin $(1.18 \mathrm{ppm})$ and titanium $(2.11 \mathrm{ppm})$ leaching

Table 4 Recycling results for $(R)-\mathrm{R}_{\mathrm{f} 6}-\mathrm{BINOL}$ in dichloromethane

\begin{tabular}{lllll}
\hline Run & Conversion $(\%)^{a}$ & ee $(\%)^{b}$ & $\mathrm{Sn}(\mathrm{ppm})^{c}$ & $\mathrm{Ti}(\mathrm{ppm})^{c}$ \\
\hline 1 & 85 & 66 & $1.24(0.02 \%)$ & $2.21(0.88 \%)$ \\
$2^{d}$ & 85 & 63 & $0.75(0.01 \%)$ & $1.99(0.83 \%)$ \\
$3^{d}$ & 82 & 58 & $2.73(0.04 \%)$ & $2.86(1.19 \%)$ \\
$4^{d}$ & 78 & 58 & $4.40(0.07 \%)$ & $4.65(1.93 \%)$
\end{tabular}

${ }^{a}$ Percent conversion determined by ${ }^{1} \mathrm{H}$ NMR spectroscopy. ${ }^{b}$ ee determined by conversion into the Mosher's acid ester followed by gc analysis. ${ }^{c}$ Metal content in product determined by ICP analysis, overall percentage shown in brackets. ${ }^{d}$ Using ligand from previous run. 
were detected. This final test demonstrates that the light fluorous approach can be used successfully in the asymmetric allylation of benzaldehyde to yield the product in high conversion and enantiopurity, whilst allowing the ligand to be isolated, recovered and reused without loss of activity or enantioselectivity.

\section{Experimental}

Proton and ${ }^{19} \mathrm{~F}$ NMR spectroscopies were carried out on a Bruker ARX 300 spectrometer at 300.14 and $282.41 \mathrm{MHz}$ respectively. Tin NMR spectroscopy was carried out on a Bruker DRX 400 spectrometer at 149.21 MHz. All chemical shifts are quoted in ppm using the high frequency positive convention; ${ }^{1} \mathrm{H}$ NMR spectra were referenced to external $\mathrm{SiMe}_{4} ;{ }^{19} \mathrm{~F}$ NMR spectra to external $\mathrm{CFCl}_{3}$ and ${ }^{119} \mathrm{Sn}$ NMR spectra to external $\mathrm{SnMe}_{4}$. Mass spectra were recorded on a Kratos Concept $1 \mathrm{H}$ mass spectrometer. GC analyses were performed using a Perkin Elmer Clarus 500 GC fitted with an SGE CYDEX-B column. Optical rotation measurements were obtained using a Perkin Elmer Polarimeter 341 at $589 \mathrm{~nm}$ using a $\mathrm{Na}-\mathrm{Hal}$ lamp. $\mathrm{Ti}\left({ }^{i} \mathrm{OPr}\right)_{4}$ was obtained from a commercial source (Aldrich), while the BINOL ligands were either purchased from a commercial source (Fluka) or synthesised by literature methods. ${ }^{5}$ Fluoroflash $\AA$ silica gel $(40 \mu \mathrm{m})$ was purchased from Fluorous Technologies. Dichloromethane and hexane were dried by refluxing over calcium hydride or sodium wire respectively under dinitrogen. The solvents were distilled under nitrogen, stored in a closed ampoule over $4 \AA$ molecular sieves and frozen-pumpedthawed three times to remove all dissolved gases.

\section{General procedure for asymmetric addition of diethylzinc to benzaldehyde}

A solution of $\mathrm{Ti}\left(\mathrm{O}^{i} \mathrm{Pr}\right)_{4}(157 \mu \mathrm{l}, 0.32 \mathrm{mmol})$ and $\mathrm{BINOL}$ ( $0.21 \mathrm{mmol}, 0.2$ equiv. $)$ in dichloromethane $(10 \mathrm{ml})$ was stirred for one hour. An additional portion of $\mathrm{Ti}\left(\mathrm{O}^{i} \mathrm{Pr}\right)_{4}$ was then added ( $314 \mu \mathrm{l}, 0.64 \mathrm{mmol})$ as well as the benzaldehyde $(107 \mu \mathrm{l}$, $1.2 \mathrm{mmol})$. The solution was then cooled to $-20{ }^{\circ} \mathrm{C}$ before adding diethylzinc $(3.12 \mathrm{mmol}, 3.12 \mathrm{ml}$ of $1 \mathrm{M}$ solution in hexane). After stirring the reaction mixture for five hours at $-20{ }^{\circ} \mathrm{C}$, it was quenched with $1 \mathrm{M}$ hydrochloric acid $(50 \mathrm{ml})$. The mixture was extracted with diethyl ether, dried, filtered and the solvent removed in vacuo to yield the product as a colourless oil contaminated with BINOL ligand. Product ee was determined using chiral GC and the absolute configuration was based on the comparison with the GC traces of the known, commercially available, enantiomerically pure compounds (CYDEX-B 30m, $90{ }^{\circ} \mathrm{C}$ for $24 \mathrm{~min}, 45{ }^{\circ} \mathrm{C} \min ^{-1}$ to $135{ }^{\circ} \mathrm{C}$, hold $5 \mathrm{~min}$. Injector: $220{ }^{\circ} \mathrm{C}$, detector: $250{ }^{\circ} \mathrm{C}$.

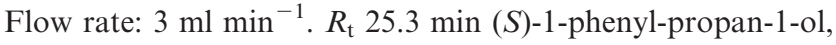
$R_{\mathrm{t}} 25.9$ min (R)-1-phenyl-propan-1-ol).

\section{Asymmetric addition using ( $R$ )-BINOL}

The general catalysis procedure was followed using $(R)$-BINOL as ligand $(0.21 \mathrm{mmol}, 60 \mathrm{mg})$. The product was collected as a colourless oil contaminated with $(R)$-BINOL. $m / z\left(\mathrm{ES}^{-}\right) 135[\mathrm{M}-\mathrm{H}]^{-}(90 \%) . \delta_{\mathrm{H}} 0.81\left(3 \mathrm{H}, \mathrm{t},{ }^{3} J_{\mathrm{HH}} 7.2 \mathrm{~Hz}\right.$,
$\left.\mathrm{CH}_{3}\right), 1.69\left(2 \mathrm{H}, \mathrm{m}, \mathrm{CH}_{2}\right), 1.98(1 \mathrm{H}$, br s, OH$), 4.47(1 \mathrm{H}, \mathrm{t}$, $\left.{ }^{3} J_{\mathrm{HH}} 6.6 \mathrm{~Hz}, \mathrm{CH}\right), 7.16-7.29(5 \mathrm{H}, \mathrm{m}, \mathrm{PhH})$. Run 1: $90 \%$ conversion, $86 \%$ ee; Run 2: $85 \%$ conversion, $90 \%$ ee; Run 3 : 90\% conversion, $90 \%$ ee.

\section{Asymmetric addition using $(R)-R_{\mathrm{f} 6}-\mathrm{BINOL}$}

The general catalysis procedure was followed using $(R)-\mathrm{R}_{\mathrm{f6}}$ BINOL as ligand $(0.21 \mathrm{mmol}, 194 \mathrm{mg})$. The product was collected as a colourless oil. $\mathrm{m} / z\left(\mathrm{ES}^{-}\right) 135[\mathrm{M}-\mathrm{H}]^{-}(90 \%) . \delta_{\mathrm{H}}$ $0.81\left(3 \mathrm{H}, \mathrm{t},{ }^{3} \mathrm{~J}_{\mathrm{HH}} 7.2 \mathrm{~Hz}, \mathrm{CH}_{3}\right), 1.69\left(2 \mathrm{H}, \mathrm{m}, \mathrm{CH}_{2}\right), 1.98(1 \mathrm{H}$, br s, OH), $4.47\left(1 \mathrm{H}, \mathrm{t},{ }^{3} J_{\mathrm{HH}} 6.6 \mathrm{~Hz}, \mathrm{CH}\right), 7.16-7.29(5 \mathrm{H}, \mathrm{m}$, $\mathrm{PhH}$ ). Run 1: $90 \%$ conversion, $77 \%$ ee; Run $2: 86 \%$ conversion, $70 \%$ ee; Run 3: $88 \%$ conversion, $75 \%$ ee.

\section{Attempted separation of $(R)-R_{\mathrm{f} 6}-\mathrm{BINOL}$ and 1-phenyl-propan- 1-ol}

The crude product and $\mathrm{R}_{\mathrm{f} 6}$-BINOL post-reaction mixture in diethyl ether was concentrated in vacuo and placed on the top of a $3 \mathrm{~cm}$ long column of FRP silica gel (1 cm in diameter). Elution with acetonitrile gave 1-phenyl-propan-1-ol which was contaminated with $(R)-\mathrm{R}_{\mathrm{f} 6}$-BINOL ligand.

\section{General procedure for asymmetric addition of allyltri-n-butyltin to benzaldehyde}

The BINOL ligand $(0.2 \mathrm{mmol})$ was added to a solution of $\mathrm{Ti}\left(\mathrm{O}^{i} \mathrm{Pr}\right)_{4}(0.3 \mathrm{ml}, 0.1 \mathrm{mmol})$ in either hexane $(20 \mathrm{ml})$ or dichloromethane $(20 \mathrm{ml})$ and the mixture was stirred for one hour. After cooling the reaction mixture to $0{ }^{\circ} \mathrm{C}$, benzaldehyde $(0.1 \mathrm{ml}, 1 \mathrm{mmol})$ was added. The reaction mixture was stirred for 10 minutes before adding allyltri- $n$-butyltin $(0.34 \mathrm{ml}$, $1.1 \mathrm{mmol}$ ) and the reaction mixture was stirred at $0{ }^{\circ} \mathrm{C}$ for a further six hours. The solvent was removed under reduced pressure and the crude mixture was then used in the general separation procedure.

\section{Determination of product (4-phenyl-1-buten-4-ol) enantiomeric excess}

4-Phenyl-1-buten-4-ol (29 $\mu \mathrm{l}, 0.2 \mathrm{mmol}$ ) was added to a solution of Mosher's acid chloride ( $2 \mathrm{ml}, 0.1 \mathrm{M}$ solution in dichloromethane, $0.2 \mathrm{mmol})$ and pyridine $(0.2 \mathrm{ml}, 2.5 \mathrm{mmol})$. After stirring the reaction mixture for 30 minutes, $1 \mathrm{M}$ hydrochloric acid was added $(3 \mathrm{ml})$. The organic phase was separated, washed with $\mathrm{NaHCO}_{3}(10 \mathrm{ml})$ and water $(10 \mathrm{ml})$, dried $\left(\mathrm{MgSO}_{4}\right)$, filtered and the solvent removed in vacuo to yield a colourless oil which was analysed by chiral GC for diastereomeric content and the absolute configuration was determined to be $R$ by comparison of the optical rotation data for 4-phenyl-1-buten-4-ol with the published specific rotation (CYDEX-B, $180{ }^{\circ} \mathrm{C}$ for $20 \mathrm{~min}$. Injector: $220{ }^{\circ} \mathrm{C}$, detector:

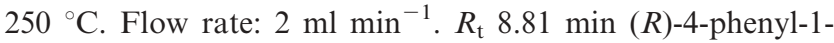
buten-4-ol, Mosher's acid ester; $R_{\mathrm{t}} 13.00$ min $(S)$-4-phenyl-1buten-4-ol, Mosher's acid ester). ${ }^{13}$

\section{Crystal data for $\left[\mathrm{SnBu}_{3}\left(2-\mathrm{O}-2^{\prime}-\mathrm{HO}-1,1^{\prime} \text {-binaphthol) }\right]_{n}\right.$}

$\mathrm{C}_{32} \mathrm{H}_{40} \mathrm{O}_{2} \mathrm{Sn}, M=575.33$, monoclinic, space group $P 2_{1}$, $a=11.2787(12), b=11.6990(13), c=11.6960(13) \AA$, 
$\beta=115.519(2)^{\circ}, U=1392.7(3) \AA^{3}, T=150 \mathrm{~K}, Z=2$, $D_{\mathrm{c}}=1.372 \mathrm{~g} \mathrm{~cm}^{-3}, F(000)=596$, colourless block, dimensions $0.26 \times 0.12 \times 0.06 \mathrm{~mm}, \mu(\mathrm{Mo}-\mathrm{K} \alpha)=0.943 \mathrm{~mm}^{-1}$. Data were measured on a Bruker SMART diffractometer using graphitemonochromated Mo-K $\alpha$ radiation $(\lambda=0.71073 \AA), 10765$ reflections measured, 5207 unique $\left(R_{\text {int }}=0.0232\right)$. An empirical absorption correction based on 6652 reflections (SADABS) was applied, maximum and minimum transmission factors of 0.86 and 0.52 respectively. The structure was solved by Patterson methods and refined using full matrix refinement based on $F^{2}$ gave $R_{1}=0.0450$ for 5031 observed data and $w R_{2}=0.1205$ for all 5207 data, GOF $=1.076$ for 317 parameters. The $\mathrm{OH}$ hydrogen was not located or refined, but was included in calculating the molecular weight and density. The highest residual electron density peak (3.94 e $\AA^{-3}$ ) was located $1.136 \AA$ from the $\mathrm{Sn}$ atom. CCDC reference numbers [257732]. See http://www.rsc.org/suppdata/gc/b4/b418039a/ for crystallographic data in .cif or other electronic format.

\section{${ }^{1} \mathrm{H},{ }^{19} \mathrm{~F}\left\{{ }^{1} \mathrm{H}\right\}$ and ${ }^{119} \mathrm{Sn}\left\{{ }^{1} \mathrm{H}\right\}$ NMR studies of material recovered from column before acid wash}

(R)-BINOL product. $\delta_{\mathrm{H}} 0.70\left(9 \mathrm{H}, \mathrm{t},{ }^{3} J_{\mathrm{HH}} 7.2 \mathrm{~Hz}, \mathrm{CH}_{3}\right), 0.80$ $\left(6 \mathrm{H}, \mathrm{m}, \mathrm{CH}_{2}\right), 1.05\left(6 \mathrm{H}, \mathrm{m}, \mathrm{CH}_{2}\right), 1.20\left(6 \mathrm{H}, \mathrm{m}, \mathrm{CH}_{2}\right), 5.06(1 \mathrm{H}$, br s, OH), 7.09 (2H, m, ArH), $7.23(2 \mathrm{H}, \mathrm{m}, \mathrm{ArH}), 7.30(2 \mathrm{H}, \mathrm{d}$, $\left.{ }^{3} J_{\mathrm{HH}} 9.0 \mathrm{~Hz}, \mathrm{ArH}\right), 7.74\left(2 \mathrm{H}, \mathrm{d},{ }^{3} J_{\mathrm{HH}} 8.6 \mathrm{~Hz}, \mathrm{ArH}\right), 7.76(2 \mathrm{H}$, d, $\left.{ }^{3} J_{\mathrm{HH}} 8.7 \mathrm{~Hz}, \operatorname{ArH}\right), 7.81\left(1 \mathrm{H}, \mathrm{d},{ }^{3} J_{\mathrm{HH}} 7.9 \mathrm{~Hz}, \operatorname{ArH}\right), 7.89$ $\left(1 \mathrm{H}, \mathrm{d},{ }^{3} J_{\mathrm{HH}} 9.2 \mathrm{~Hz}, \mathrm{ArH}\right) . \delta_{\mathrm{Sn}} 105.47$ (2Sn, s), 115.63 (1Sn, s).

$(\boldsymbol{R})-\mathbf{R}_{\mathbf{f 6}}$-BINOL product. $\delta_{\mathrm{H}} 0.82\left(9 \mathrm{H}, \mathrm{t},{ }^{3} J_{\mathrm{HH}} 7.3 \mathrm{~Hz}, \mathrm{CH}_{3}\right)$, $1.06\left(6 \mathrm{H}, \mathrm{m}, \mathrm{CH}_{2}\right), 1.24\left(6 \mathrm{H}, \mathrm{m}, \mathrm{CH}_{2}\right), 1.40\left(6 \mathrm{H}, \mathrm{m}, \mathrm{CH}_{2}\right), 5.21$ $\left(1 \mathrm{H}\right.$, br s, OH), $7.01\left(2 \mathrm{H}, \mathrm{d},{ }^{3} J_{\mathrm{HH}} 8.1 \mathrm{~Hz}, \mathrm{ArH}\right), 7.22(4 \mathrm{H}, \mathrm{m}$, ArH), $7.77\left(1 \mathrm{H}, \mathrm{d},{ }^{3} J_{\mathrm{HH}} 8.8 \mathrm{~Hz}, \operatorname{ArH}\right), 7.85\left(1 \mathrm{H}, \mathrm{d},{ }^{3} J_{\mathrm{HH}}\right.$ $7.8 \mathrm{~Hz}, \mathrm{ArH}), 7.99\left(2 \mathrm{H}, \mathrm{d},{ }^{3} J_{\mathrm{HH}} 7.2 \mathrm{~Hz}, \mathrm{ArH}\right) . \delta_{\mathrm{F}}-80.79(6 \mathrm{~F}$, $\left.\mathrm{t},{ }^{4} J_{\mathrm{FF}} 9.2 \mathrm{~Hz}, \mathrm{CF}_{3}\right),-109.59\left(4 \mathrm{~F}, \mathrm{~m}, \alpha-\mathrm{CF}_{2}\right),-121.44(8 \mathrm{~F}, \mathrm{~m}$, $\left.2 \times \mathrm{CF}_{2}\right),-122.78\left(4 \mathrm{~F}, \mathrm{~m}, \mathrm{CF}_{2}\right),-126.12\left(4 \mathrm{~F}, \mathrm{~m}, \mathrm{CF}_{2}\right) . \delta_{\mathrm{Sn}}$ 106.20 (2Sn, s), 123.05 (1Sn, s).

\section{Asymmetric addition of allyltri-n-butyltin using ( $R$ )-BINOL}

The general catalysis procedure was followed using $(R)$-BINOL (57 mg, $0.2 \mathrm{mmol}$ ) as ligand. The product was collected as a colourless oil contaminated with BINOL material. $m / z\left(\mathrm{ES}^{+}\right) 149[\mathrm{M}+\mathrm{H}]^{+}(23 \%) . \delta_{\mathrm{H}} 2.32(1 \mathrm{H}$, br $\mathrm{s}$, $\mathrm{OH}), 2.54\left(2 \mathrm{H}, \mathrm{m}, \mathrm{CH}_{2}\right), 4.74\left(1 \mathrm{H}, \mathrm{dd},{ }^{3} J_{\mathrm{HH}} 7.0 \mathrm{~Hz},{ }^{3} J_{\mathrm{HH}}\right.$ $5.8 \mathrm{~Hz}, \mathrm{CH}), 5.15\left(1 \mathrm{H}, \mathrm{m},=\mathrm{CH}_{2}\right), 5.20\left(1 \mathrm{H}, \mathrm{dm},{ }^{3} J_{\mathrm{HH}} 9.0 \mathrm{~Hz}\right.$, $\left.=\mathrm{CH}_{2}\right), 5.84(1 \mathrm{H}, \mathrm{m}, \mathrm{HC}=), 7.24-7.39(5 \mathrm{H}, \mathrm{m}, \mathrm{PhH})$. Run 1: 90\% conversion, $82 \%$ ee; Run 2: $90 \%$ conversion, $78 \%$ ee; Run 3: $88 \%$ conversion, $78 \%$ ee.

\section{Asymmetric addition of allyltri- $n$-butyltin using $(R)-R_{\mathrm{f} 6}-\mathrm{BINOL}$}

The general catalysis procedure was followed using $(R)-\mathrm{R}_{\mathrm{f6}}$ BINOL (184 mg, $0.2 \mathrm{mmol})$ as ligand in hexane. The product was collected as a colourless oil. $m / z\left(\mathrm{ES}^{+}\right) 149[\mathrm{M}+\mathrm{H}]^{+}(26 \%)$. $\delta_{\mathrm{H}} 2.32\left(1 \mathrm{H}\right.$, br s, OH), $2.54\left(2 \mathrm{H}, \mathrm{m}, \mathrm{CH}_{2}\right), 4.74\left(1 \mathrm{H}, \mathrm{dd},{ }^{3} J_{\mathrm{HH}}\right.$ $\left.7.0 \mathrm{~Hz},{ }^{3} J_{\mathrm{HH}} 5.8 \mathrm{~Hz}, \mathrm{CH}\right), 5.15\left(1 \mathrm{H}, \mathrm{m},=\mathrm{CH}_{2}\right), 5.20(1 \mathrm{H}, \mathrm{dm}$, $\left.{ }^{3} J_{\mathrm{HH}} 9.0 \mathrm{~Hz},=\mathrm{CH}_{2}\right), 5.84(1 \mathrm{H}, \mathrm{m}, \mathrm{HC}=), 7.24-7.39(5 \mathrm{H}, \mathrm{m}$, $\mathrm{PhH}$ ). Run 1: $86 \%$ conversion, $74 \%$ ee; Run $2: 90 \%$ conversion, $78 \%$ ee; Run 3: $88 \%$ conversion, $74 \%$ ee.
General procedure for the separation of BINOL and 4-phenyl-1buten-4-ol

A standard reaction mixture was concentrated in vacuo and the residue placed onto the top of a column of silica gel, FRP silica gel, $\mathrm{C}_{8}$-reverse phase silica gel or powdered PTFE (3 cm long, $1 \mathrm{~cm}$ diameter). Acetonitrile was then used as elutant to recover the product. Diethyl ether was used as the second elutant to recover any ligand not eluted with the acetonitrile phase. This was washed with $4 \mathrm{M} \mathrm{HCl}$, the organic layer separated and dried and the solvent removed under reduced pressure to yield free BINOL. Only when both FRP silica gel and $(R)-\mathrm{R}_{\mathrm{f} 6}$-BINOL were used was complete separation of the ligand and product possible. After acid washes of the diethyl ether fraction and removal of the solvent, the recovered $(R)-\mathrm{R}_{\mathrm{f} 6}$-BINOL was used in three further catalytic runs following the same catalysis procedure. The general separation procedure was then used to recover the ligand and separate the 4-phenyl-1-buten-4-ol product. After each run, the product was washed with $6 \mathrm{M}$ hydrochloric acid and the $\mathrm{Sn}$ and $\mathrm{Ti}$ levels determined by ICP analysis of the wash. Figures in brackets indicate percentage of metal added at the outset which is present in the product. Run 1: $85 \%$ conversion, 66\% ee. Sn: 1.24 ppm (0.02\%) Ti: 2.21 ppm (0.88\%); Run 2: $85 \%$ conversion, $63 \%$ ee. Sn: $0.75 \mathrm{ppm}(0.01 \%)$ Ti: $1.99 \mathrm{ppm}$ $(0.83 \%)$; Run $3: 82 \%$ conversion, $58 \%$ ee. $\mathrm{Sn}: 2.73 \mathrm{ppm}(0.04 \%)$ Ti: $2.86 \mathrm{ppm}(1.19 \%)$; Run 4: 78\% conversion, $58 \%$ ee. $\mathrm{Sn}$ : 4.40 ppm (0.07\%) Ti: 4.65 ppm (1.93\%).

\section{Acknowledgements}

We thank the Royal Society (EGH, AMS), the EPSRC (AJW) and Merck GmbH (AJW) for financial support.

John Fawcett, Eric. G. Hope, Alison M. Stuart* and Andrew J. West Department of Chemistry, University of Leicester, Leicester, UK, LE17RH. E-mail: amc17@le.ac.uk; Fax:+44116252 3789;

Tel: +441162522136

\section{References}

1 Handbook of Fluorous Chemistry, ed. J. A. Gladysz, D. P. Curran and I. T. Horváth, Wiley-VCH Verlag GmbH \& Co. KgaA, Weinheim, Germany, 2004.

2 D. P. Curran, Synlett, 2001, 1488.

3 W. Zhang, Tetrahedron, 2003, 59, 4475.

4 B. Croxtall, E. G. Hope and A. M. Stuart, Chem. Commun., 2003, 2430.

5 E. G. Hope, A. M. Stuart and A. J. West, Green Chem., 2004, 6, 345.

6 J. Vaughan-Spickers, A. M. Stuart, E. G. Hope and A. J. West, Eur. Patent Appl., 2004, EP04022878.5.

7 D. J. Birdsall, E. G. Hope, A. M. Stuart, W. Chen, Y. Hu and J. Xiao, Tetrahedron Lett., 2001, 42, 8551.

8 F.-Y. Zhang, C.-W. Yip, R. Cao and A. S. C. Chan, Tetrahedron: Asymmetry, 1997, 8, 585.

9 Y. Nakamura, S. Takeuchi and Y. Ohgo, J. Fluorine Chem., 2003, 120, 121.

10 Y.-Y. Yin, G. Zhao, Z.-S. Qian and W.-X. Yin, J. Fluorine Chem., $2003,120,117$

11 H. Renter and D. Schröder, Acta Crystallogr. Sect. C: Struct. Commun., 1993, 49, 954.

12 H. C. Aspinall, J. F. Bickley, J. L. M. Dwyer, N. Greeves and A. Steiner, Angew. Chem., Int. Ed., 2000, 39, 2858.

13 G. E. Keck, K. H. Tarbet and L. S. Geraci, J. Am. Chem. Soc., 1993, 115, 8467. 